\title{
M-government Adoption Research Trends: A Systematic Review
}

\section{Thamer Alshammari}

Faculty of Information Technology

Monash University

Melbourne, Australia

Email: thamer.alshammari@monash.edu

\section{Yen Cheung}

Faculty of Information Technology

Monash University

Melbourne, Australia

Email: yen.cheung@monash.edu

\section{Chris Messom}

Faculty of Information Technology

Monash University

Melbourne, Australia

Email: christopher.messom@monash.edu

\section{Abstract}

Mobile government (m-government) adoption is a relatively new area in the field of information systems which has only started to attract research attention in the last few years. This paper presents a systematic review of m-government adoption to investigate its current and future research directions. This paper reviews 30 studies that were published in scientific journals and conferences during the last five years on the topic of m-government. It analyzes the research in terms of research methodology, theories used, stakeholders, limitations and recommendations. Results of this paper indicate that the quantitative approach is the most commonly used methodology and the Technology Acceptance Model is the most prevalent theory used in m-government research. A majority of reported limitations of the published research are related to samples and generalizability. Following an analysis of the results, more focus on stakeholders' roles in m-government adoption is suggested and this is believed to be a significant agenda for future research in this area.

Keywords m-government, adoption, stakeholders, literature review. 


\section{Introduction}

M-government is defined as the delivery of public services including transactions on mobile devices like mobile phones, pagers and personal digital assistants (Misra 2009). To enhance their services to reach a wider population, governments around the world have adopted mobile technology as a new channel for the provision of services (Ahmed and Khalid 2017). For example, a main benefit of m-government is that public sector workers, like law enforcement officials and home healthcare providers, can complete some tasks with mobile devices whilst they are out in the field (Nguyen et al. 2015). On the other hand, citizens can benefit from real-time information access and personalized services (Abu-Shanab et al. 2016).

The literature shows a gap between governmental efforts to use mobile devices as platforms for providing public services and the adoption of these services by citizens. Scholars stated that many governments around the world have realized the importance of providing public services via mobile devices and have implemented m-government (Glood et al. 2016b). On the other hand, some studies have shown that the current adoption level of m-government by citizens is low in many countries, such as India (Saxena 2017) and Tanzania (Mandari et al. 2017). Furthermore, the World Bank (2012) reported that although about half of the world's population use the internet regularly, most fail to utilize m-government services (Alssbaiheen and Love 2015).

Recent studies have started investigating the adoption of m-government (Alotaibi and Roussinov 2016; Wang 2014). Current $\mathrm{m}$-government research has considered the roles of stakeholders, like citizens and governments (Wang 2014). However, it is believed that other types of stakeholders particularly those who are involved in decision-making and those in the private sectors (e.g. mobile service providers) also play a significant role in m-government adoption (Carrol 2006). In this paper, we discuss the importance of different stakeholders such as business practitioners as well as government officials and citizens in $\mathrm{m}$-government adoption. This study aims to conduct a systematic review of the adoption of $\mathrm{m}$ government by examining and analyzing empirical studies that investigated the adoption of $\mathrm{m}$ government in terms of publication dates, methodologies, theories, stakeholders, limitations and recommendations. Only empirical studies were included in the analysis so we can analyze the papers based on the type of research methodology used.

The results of this study will help researchers understand the development of studies that investigated the adoption of m-government, as well as future research trends in this area. The remainder of this paper is structured as follows. Firstly, it presents the literature search approach. Secondly, it reviews and analyzes the studies found in the literature. Thirdly, it discusses the main findings and future directions. Finally, it provides concluding remarks on the research.

\section{Literature search approach}

A combination of sets of keywords were used to search for the relevant studies. The keywords are as follows: "adoption of m-government", "adoption of mgovernment", and "adoption of mobile government" using the OR operator in Google Scholar, as it is the most powerful and comprehensive search engine for academic papers (Ortega 2015). The search setting was customized to search for studies that were published between 2012 and 2017. There are two reasons for choosing this period:

(1) Due to the recent rapid changes in m-government services and the limited availability of mgovernment services seven years ago only the above-mentioned period is included. According to Galvez and Youngblood (2016) in 2012, governments in some countries rapidly implemented m-government services;

(2) By 2012, mobile phones became the most popular devices to access the internet (Lee and Rotoloni 2013).

A total of 183 studies were retrieved based on the search criteria from scholarly journals and conferences. After the process of narrowing down the studies to those which empirically investigated the adoption of m-government, 30 studies were found to be relevant (see Figure 1). It is worth mentioning that, these studies are published in the Information Systems and Public Administration disciplines. These studies were reviewed and detailed information was extracted for analysis, which is discussed in the following section. 


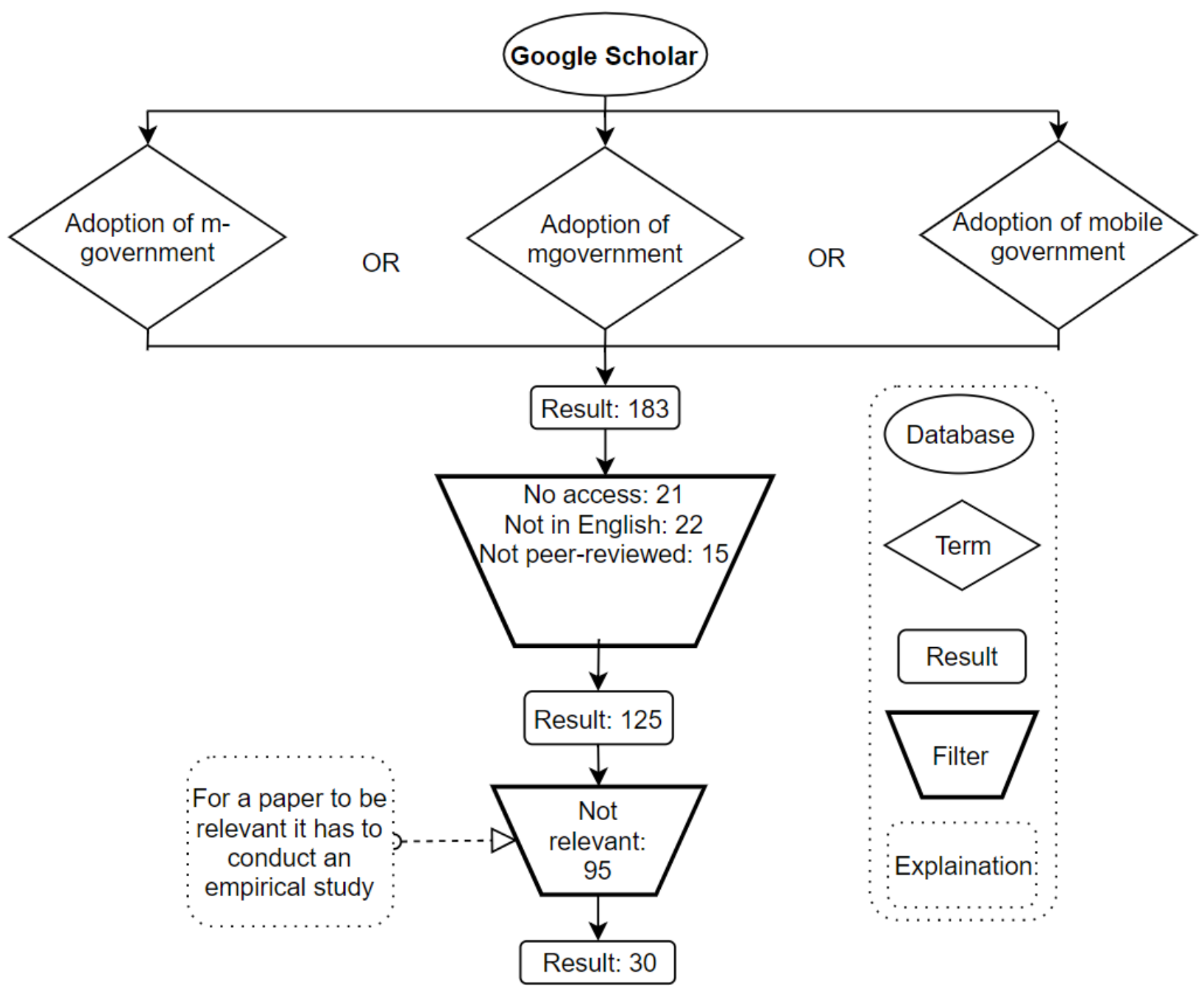

Figure 1: Flowchart of the search strategy

\section{Literature analysis}

This section presents the analysis of data extracted from 30 papers that are judged to be relevant to mgovernment empirical research. The analysis is based on the publication dates, the approaches applied, the theories used, and the types of stakeholders considered, as well as examining the limitations and trends in m-government studies.

\subsection{General analysis}

\subsubsection{Dates analysis}

A time analysis was performed to understand the developments and trends of studies in the research area.

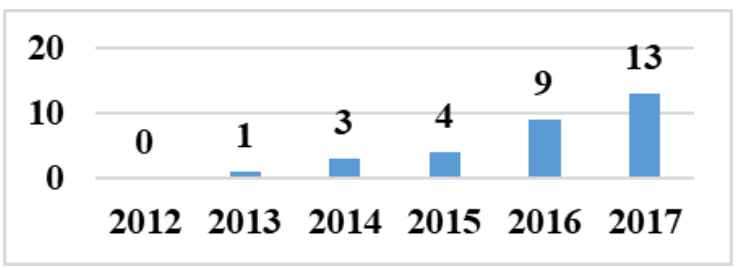

Figure 2: Number of publications per year (2012-2017)

As seen in Figure 2, the number of publications started to increase dramatically in 2016. 22 of the 30 studies were conducted in the last two years. This could be due to the increase in the number of mgovernment services and the reduction in the prices of mobile devices (Fontelo et al. 2015). In summary, research in m-government adoption is a relatively new and trending area of research. 


\subsubsection{Research methodologies}

The quantitative research methodology is the most commonly employed research methodology in the context of the adoption of m-government (26 out of 30), whereas qualitative data were collected in only four studies. Although studies in related areas, such as electronic government (e-government), have adopted the mixed research methodology (Gil-García 2006), as yet no study has used the mixed research methodology in the field of m-government.

Interestingly, the qualitative methodology was not used in this area of research until 2016. This could be due to the limited use of m-government services prior to 2016, which might have influenced data collection.

\subsection{Theories used}

It has been noted that while 10 studies applied no theories, the other 20 studies used either theories (incorporating external factors) or a combination of theories. Amongst these 20 studies, 13 used the Technology Acceptance Model (TAM) and 3 studies used the Diffusion of Innovation (DOI). The Unified Theory of Acceptance Use of Technology (UTAUT) and Unified Theory of Acceptance Use of Technology 2 (UTAUT2) were used twice each. The Theory of Reasoned Action (TRA), Theory of Planned Behavior (TPB), Social Cognitive Theory (SCT), and Information System Success Model (IS Success Model) were each used only once in the group.

\begin{tabular}{|l|l|l|}
\hline Theory & N & Source \\
\hline TAM & 13 & $\begin{array}{l}\text { (Ahmad and Khalid 2017; Jasimuddin et al. 2017; Alotaibi and Roussinov } \\
\text { 2017a; Saadi et al 2017; Almuraqab 2017; Alotaibi et al. 2017; Baabdullah } \\
\text { et al 2016; Alotaibi et al. 2016; Abu-Shanab et al. 2016; Abaza and Saif } \\
\text { 2015; Alrowili et al. 2015; Ohme 2014; Wang 2014) }\end{array}$ \\
\hline DOI & 3 & (Mandari et al. 2017; Saadi et al 2017; Almuraqab 2017) \\
\hline UTAUT2 & 2 & (Baabdullah et al 2017; Babullah et al. 2015) \\
\hline UTAUT & 2 & (Migdadi 2013; Liu et al. 2014) \\
\hline TRA & 1 & (Abu-Shanab et al. 2016) \\
\hline TPB & 1 & (Ohme 2014) \\
\hline SCT & 1 & (Abu-Shanab et al. 2016) \\
\hline IS Success Model & 1 & (Glood et al. 2016a) \\
\hline
\end{tabular}

Table 1. Theories used to investigate the adoption of m-government

The most common combination of theories across these studies is TAM and DOI, as two studies incorporated both of these models. It has been observed that, apart from one study which applied DOI alone, all studies that used theories either incorporated a number of theoretical frameworks or added external factors to the applied theory. Interestingly, the second most used theory (DOI) is the newest emerging theory in the context of m-government adaption; it was adopted by three studies that were published in 2017 (see Table 1).

It has been noted that most theories emphasize the impact of users' beliefs, attitudes, and characteristics on successful m-government adoption. Given this, users themselves are an essential component of the success of m-government. Since m-government is a complex system that may not just involve end-users (citizens), but also other potential individuals/groups, we attempt to understand the different types of stakeholders who might also have some interests in m-government. The following section analyzes how the existing literature looked at the different types of stakeholders.

\subsection{Stakeholders analysis}

According to Freeman (1984), "A stakeholder in an organization is any group or individual who can affect or is affected by the achievement of the organization's objective" (p. 46). He also stated that for any business to be successful, it has to create value for its stakeholders. There is a rising recognition of stakeholders' roles in the adoption of new technologies, and considering stakeholders' perceptions is important to understand the acceptance or rejection of new technologies. Although stakeholder theory was established in the private sector, many researchers argued that it can also be used in the public 
sector. For example, Scholl (2001) used this theory in the context of e-government to identify and understand the role of stakeholders in e-government projects.

Recent studies, in the field of m-government, have begun to address the role of stakeholders by introducing the concept of public value (Wang 2014). Public value is defined as "the value created by government through services, laws regulation and other actions" (Kelly et al. 2002, p. 4). Wang (2014) stated that the theory of perceived value attracts many researchers attention, as it is believed that creating value for stakeholders is the ultimate service goal. Therefore, "only the stakeholders, not the government, can determine what is truly of value to them" (Chatfield and AlHujran 2007, p. 54). As a result, we have analyzed the collected papers based on the identification and inclusion of stakeholders. In Figure 3 "Identified stakeholders" refers to studies that only mentioned a number of different stakeholders, while "Identified and Included stakeholders" refers to studies that mentioned a number of different types of stakeholders and included them in their research.
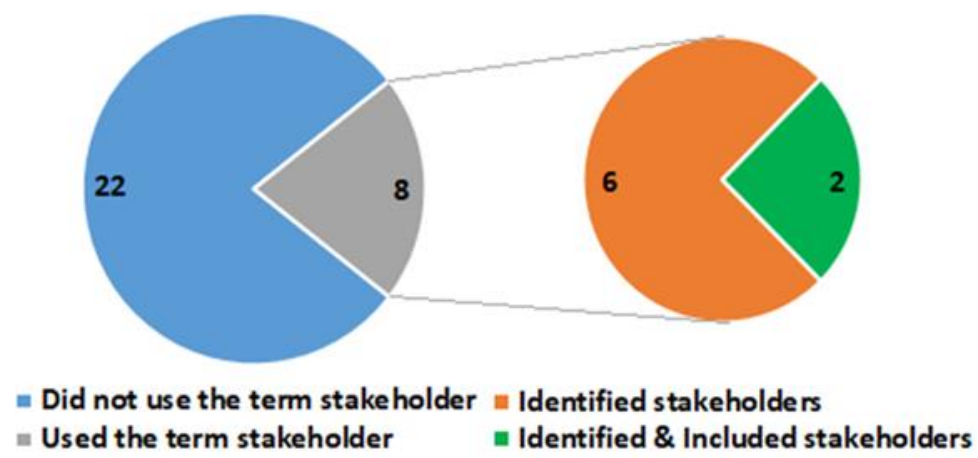

Figure 3. Classification of studies based on stakeholders' perceptions analysis

Figure 3 shows that even though m-government adoption is a topic which is beginning to attract an increasing amount of interest, few studies have looked into the stakeholders' perceptions with regard to providing governmental services through mobile devices. Eight out of thirty studies referred to stakeholders, but only two of those eight studies investigated the perceptions of stakeholders. Table 3 presents the development of the concept 'stakeholder' in the field of m-government over the last four years.

\begin{tabular}{|l|l|l|}
\hline Year & Research development & Source \\
\hline 2014 & $\begin{array}{l}\text { The first use of the term to refer to citizens as stakeholders in m- } \\
\text { government. }\end{array}$ & (Wang 2014) \\
\hline 2016 & $\begin{array}{l}\text { The first use of the term to refer to government officials, business } \\
\text { practitioners, and ICT managers as stakeholders in m-government. }\end{array}$ & $\begin{array}{l}\text { (Faisal and Talib } \\
\text { 2016) }\end{array}$ \\
\cline { 2 - 4 } & $\begin{array}{l}\text { The first time to consider perceptions of stakeholders other than } \\
\text { citizens, namely government officials, business practitioners, and ICT } \\
\text { managers. }\end{array}$ & $\begin{array}{l}\text { (Faisal and Talib } \\
\text { 2016; Chen et al. } \\
\text { 2016) }\end{array}$ \\
\hline 2017 & $\begin{array}{l}\text { The first use of the term to refer to applications developers as } \\
\text { stakeholders in m-government. }\end{array}$ & $\begin{array}{l}\text { (Alotaibi and } \\
\text { Roussinov 2017b; } \\
\text { Saadi et al. 2017) }\end{array}$ \\
\hline
\end{tabular}

Table 2. Development of researches in terms of stakeholders' inclusion

Since 2014, the concept of stakeholder has developed in the area of m-government adoption, and more recent studies have emphasized the importance of the stakeholders (Alotaibi and Roussinov 2017b; Faisal and Talib 2016). Nevertheless, for two years after the importance of stakeholders was first acknowledged by scholars in 2014, none had considered examining the perceptions of any other stakeholders besides the citizens. In 2016, Faisal and Talib (2016) and Chen et al. (2016) were the first two studies to investigate the adoption of $\mathrm{m}$-government from the perspectives of different stakeholders. In order to find some explanations for the delayed consideration of stakeholders' perspectives in the adoption of m-government, we studied the similar context of e-government. Misra (2015) argued that most of the earlier studies assessed e-government services in terms of efficiency and effectiveness; however, the provided services have recently evolved to a level of maturity where citizens and other stakeholders need to be involved in order to avoid digital divide. 
To provide more supporting arguments for the importance of stakeholders, we further examined the egovernment (Rowley 2011), electronic commerce (Hanna 2016), and electronic learning contexts (Aquino 2015) and found that these studies recognized the role of stakeholders in the adoption of new technologies. Therefore, we argue that the role of stakeholders is also important in m-government. Based on the stakeholder theory, a stakeholder in m-government is any group/individual who can affect or is affected by the achievement of a successful m-government. This is evident in the case of the telecommunication companies (as stakeholders); they directly affect the adoption of m-government, as they are the ones who run the network that connects citizens with governments. In other words, even if both citizens and governments are willing to adopt m-government, but the telecommunication infrastructure built by mobile operators is poor, then the m-government will not succeed. Moreover, telecommunication companies are indirectly affected by $\mathrm{m}$-government because the adoption of $\mathrm{m}$ government increases the use of mobiles, which will increase the companies' revenues (NyembaMudenda and Chigona 2013).

\subsection{Limitations of reviewed studies}

The analysis of the collected papers revealed different types of limitations. Some of these limitations were specific to a study and were reported only once. Other limitations seemed to be common across different studies in the field. The frequency of these limitations differed from rare to very common. Table 3 presents the type and description of each limitation, as well as the studies that have reported the limitation.

\begin{tabular}{|c|c|c|c|}
\hline Limitation & Description & $\mathrm{N}$ & Source \\
\hline $\begin{array}{l}\text { Sample and } \\
\text { Generalizability }\end{array}$ & $\begin{array}{l}\text { These studies included only a single } \\
\text { group of users (e.g. students), } \\
\text { sampled from one region, and had } \\
\text { a limited number of participants. } \\
\text { The non-random sample led to } \\
\text { biased results, or the study was } \\
\text { context specific. }\end{array}$ & 15 & $\begin{array}{l}\text { (Ahmad and Khalid 2017; Alotaibi and } \\
\text { Roussinov 2017b; Wirtz and } \\
\text { Birkmeyer 2017; Alotaibi and } \\
\text { Roussinov 2017a; Baabdullah et al } \\
\text { 2017; Almarashdeh, and Alsmadi 2017; } \\
\text { Abu-Shanab et al. 2016; Glood et al. } \\
\text { 2016a; Glood et al. 2016b; ElSherif } \\
\text { 2016; Alrowili et al. 2015; Ohme 2014; } \\
\text { Liu et al. 2014; Wang 2014; Al-Hujran, } \\
\text { and Migdadi 2013) }\end{array}$ \\
\hline $\begin{array}{l}\text { Factors } \\
\text { variables }\end{array}$ & $\begin{array}{l}\text { These studies were either limited to } \\
\text { a few factors or did not consider the } \\
\text { demographic variables. }\end{array}$ & 6 & $\begin{array}{l}\text { (Saxena 2017; Jasimuddin et al. 2017; } \\
\text { Mandari et al. 2017; Almarashdeh and } \\
\text { Alsmadi 2017; Saadi et al. 2017; Glood } \\
\text { et al. 2016a) }\end{array}$ \\
\hline $\begin{array}{l}\text { Instrument } \\
\text { validation }\end{array}$ & $\begin{array}{l}\text { Instruments were used for the first } \\
\text { time or translated into another } \\
\text { language without validation. }\end{array}$ & 2 & $\begin{array}{l}\text { (Abu-Shanab et al. 2016; Abu-Shanab } \\
\text { and Haider 2015) }\end{array}$ \\
\hline Analysis & $\begin{array}{l}\text { Descriptive analysis rather than } \\
\text { inferential analysis. }\end{array}$ & 2 & $\begin{array}{l}\text { (Alotaibi and Roussinov 2017a; } \\
\text { Babullah et al. 2015) }\end{array}$ \\
\hline
\end{tabular}

Table 3. Limitations found in the reviewed literature

It was found that seven studies did not report any limitation. On the other hand, fifteen studies (half of the studies) reported some type of limitations in their samples. This is problematic especially in the quantitative studies as none of the qualitative studies reported any limitations related to their sample. For instance, Omhe (2014) and ElSherif et al. (2016) surveyed only a specific group of people who are familiar with m-government services, which might have led to biased results and a higher acceptance of m-government. Some researchers also acknowledge the limitations of not incorporating sufficient factors, choosing the right factors, or considering demographic variables.

Moreover, we critique the practices and conclusions of the reviewed papers. Due to space limit, Table 4 summarizes some of the important limitations in the extant literature.

\begin{tabular}{|l|l|}
\hline Study & Limitation \\
\hline (Molnár et al. & $\begin{array}{l}\text { The study investigated how usability can affect elderly people's acceptance of m- } \\
\text { government. It is found that the higher the maturity level of m-government service, } \\
\text { the lower the elderly people acceptance become. Although this can be seen as an } \\
\text { interesting finding, however, the study fails to offer an adequate explanation for the } \\
\text { relationship between elderly acceptance and m-government maturity level. }\end{array}$ \\
\hline
\end{tabular}




\begin{tabular}{|l|l|}
\hline $\begin{array}{l}\text { (Alotaibi and } \\
\text { Roussinov } \\
\text { 2017a) }\end{array}$ & $\begin{array}{l}\text { They employed satisfaction as a determinant to actual use, assuming potential } \\
\text { adopters can form satisfaction prior to using m-government. However, the authors } \\
\text { did not take into account the pre-existing studies that prove satisfaction can only be } \\
\text { derived from direct experience (Tian-Cole et al. 2002). In other words, although } \\
\text { potential adopters can have an impression of the 'ease of use' of m-government they } \\
\text { have never used, satisfaction can only be formed after using m-government. }\end{array}$ \\
$\begin{array}{l}\text { (Almarashdeh } \\
\text { and Alsmadi } \\
\text { 2017; Abaza } \\
\text { and Saif 2015) }\end{array}$ & $\begin{array}{l}\text { Both studies tested trust in technology (TIT), but not trust in the government (TIG). } \\
\text { While TIT is important, many other researchers proved that TIG is as important and } \\
\text { ine studies were conducted in the same context (m-government), Almarashdeh and } \\
\text { Alsmadi (2017) found that TIT significantly affects the intention to use m- } \\
\text { government, while Abaza and Saif (2015) found that TIT has not affect the intention } \\
\text { to use m-government. The findings would have been much more persuasive if the } \\
\text { authors had considered investigating TIG, which may have explained the } \\
\text { inconsistent results. Otherwise, the studies should have at least justified the } \\
\text { exclusion of TIG. }\end{array}$ \\
\hline
\end{tabular}

Table 4. Some important limitations

\subsection{Recommendations of reviewed studies}

To identify which types of studies will make significant contributions to the field, a number of future research recommendations were extracted from the collected papers. The most common recommendations were related to the use of additional or more relevant factors and variables. For instances, demographic variables (Saxena 2017; Jasimuddin et al. 2017; Saadi et al. 2017; Almuraqab 2017), cost (Glood et al. 2016a; ElSherif et al. 2016; Abu-Shanab and Haider 2015) and security (Glood et al. 2016a; Glood et al. 2016b; Alrowili et al. 2015).

The second most common recommendation is related to the samples of the studies. Indeed, seven studies recommended increasing the number of participants or including participants from diverse groups like different age groups, education levels, and profession types (Almarashdeh, and Alsmadi 2017; Alotaibi and Roussinov 2017b). Other less common recommendations included testing the model in different contexts (Alotaibi et al. 2017), conducting a longitudinal study (Ahmad and Khalid 2017), utilizing a mixed-method approach (Baabdullah et al. 2017), and capturing the perceptions of stakeholders such as citizens, business practitioners, and ICT managers (Faisal and Talib 2016).

\section{Discussion}

The findings presented in the previous section indicate that empirical investigative studies concerning the adoption of m-government only started recently around 2013. The analysis also reveals that interest in m-government has dramatically increased over the last two years. It is apparent that m-government will attract even more attention, as both m-government and its associated technologies are evolving at a very fast pace. Availability and affordability of mobile technology will further influence interest in this field.

Analysis of the methodologies employed by past research indicated that little or no exploitation of the mixed methodology by current studies. As the mixed research methodology can provide a deeper insight and more explanations of the findings (Cao et al. 2006), there is a need for mixed methodology in $\mathrm{m}$ government studies. According to Cao et al. (2006), the mixed research methodology is more efficient, in deriving information, than a single methodology (quantitative or qualitative). This is because the mixed research methodology combines the strengths of each quantitative and qualitative and overcomes the weaknesses of using a single methodology (Johnson and Onwuegbuzie 2004). With a broader coverage and greater affordability of mobile technology in the coming years, it may be possible to collect richer data sets for more in-depth analysis of m-government adoption.

In terms of theories applied to m-government research, the studies in m-government adoption favored the TAM over other theories. Despite, the fact that many researchers have criticized the TAM; for instance, Gillenson and Sherrell (2002) pointed out TAM's failure to account for social influence on the adoption of new technologies, and Chen and Huang (2006) are critical of this model's low explanatory power. This has led to further investigations of the studies that adopted TAM, in which we found that current studies have addressed these criticisms by incorporating other theories, such as DOI (Saadi et al. 2017), or considering external factors, such as social influence (Jasimuddin et al. 2017). Analysis of the current studies showed that TAM was the most used theory because of its flexibility in incorporating external factors and other theories. However, further investigations are needed to gain insight into the 
reasons why other theories have not attained as much attention as TAM and what other theories outside the Information Systems discipline may be relevant for studying m-government adoption. Finally, to acquire a deeper understanding of the research topic, we need to investigate the adoption of $\mathrm{m}$ government by considering theories that have not yet been tested. Also, a comparison of findings based on current theories with new external factors and emerging theories may also provide more insights into the research area.

The introduction of the concept of stakeholders in m-government studies can be attributed to rapid developments in m-government, as early studies seem to focus on service efficiency and effectiveness. However, interest has now shifted toward citizens and the value they can gain from m-government. Without citizen's adoption of the provided services, m-government will not be successful. Moreover, recent interest of private sectors, especially mobile service providers, in m-government has increased because successful adoption leads to the increase in mobile subscriptions and as a result their revenue will grow. Although the analysis indicated a growing recognition of the importance of stakeholders' perspectives in the context of m-government, insufficient work has included the perceptions of different stakeholders. In fact, this topic requires more in-depth studies that investigate the perceptions of the various stakeholders to develop a holistic view of the adoption of m-government.

Analysis of the limitations of the collected studies showed that the most reoccurring limitations were related to the samples and generalizability of the findings. To address these issues, future research needs to include larger samples from different groups. As further development and adoption of m-government take place over time, having a sufficient sample size for research will not be a problem. It was also found that some studies acknowledged the limitations of not incorporating sufficient factors, choosing the right factors, or considering demographic variables. Researchers must consider the types of factors, i.e. both dependent (such as intention to use and continue to use) and independent factors (such as cost and security) when studying m-government. Indeed, this is because there exist many alternatives, and researchers need to select the right factors depending on the context as the influence of these factors differs in different countries and cultures. The inclusion of demographic variables can also reveal new findings, for example the influence of gender and level of education on the adoption of m-government. Other studies reported a lack of instrument validation, which could be done by conducting a pilot test, or the use of descriptive analysis rather than inferential analysis, in which the findings can be generalized to a larger population.

The analysis also included investigations of the recommendations for future research. The findings illustrate the importance of investigating demographic variables as well as the factors like cost and security as they were the top most recommended factors by recent studies (Saxena 2017; Glood et al. 2016a). It was also recommended that the sample should cover a diverse group of end-users, as a number of studies focused on only a single type of end-users (e.g. students, elderly people, or youths), which might have led to biased results. Despite the fact that only one study (Faisal and Talib 2016) explicitly recommended stakeholders' inclusion, this is actually believed to be the most significant recommendation because it will provide a deeper picture of the factors that affect the adoption of $\mathrm{m}$ government.

In summary, investigating the adoption of m-government by employing the mixed methodology will provide greater insights and therefore, contribute to the field of $\mathrm{m}$-government. There is room for future studies to investigate the adoption of m-government incorporating theories with external factors such as cost and security. This is because these factors were the top recommendations by the current studies. Investigating the perceptions of different stakeholders is important for developing a holistic view of the adoption of $\mathrm{m}$-government. It is also important for future research to address the limitations of current studies (e.g. sample and generalizability). Finally, future research can also contribute to the field by testing the effect of demographic variables on the adoption of m-government.

\section{Conclusion and recommendations for further work}

This paper reviewed the literature of m-government adoption using a systematic review of studies published between 2012 and 2017. Out of 183 studies, 30 studies were found to be relevant for this study. The findings showed that the quantitative research methodology was the most adopted research approach, while only a few studies adopted the qualitative research methodology, and no study adopted the mixed research approach. While most studies employed TAM, other models, such as DOI and UTAUT, have not had as much attention. Results of the analysis showed that the role of stakeholders (e.g. mobile service providers) on the successful adoption of m-government has recently been considered and their perceptions are as important as those of governments and citizens. Therefore, future studies can make valuable contributions to the field by considering the perceptions of stakeholders like mobile 
service providers. While most limitations were related to the sample and generalizability of the finding, most future research recommendations were related to factors and demographic variables.

Future research should widen the scope of the research to include studies in other disciplines, i.e. mobile health, mobile education, and mobile democracy. Future research should also consider investigating stakeholders' perceptions of the factors that affect m-government adoption. It is also worthwhile to consider other tested theories outside the realm of Information Systems besides those mentioned in this paper to provide more insights into the phenomenon. Last but not least another related area of research is to compare e-government research with m-government research to determine if knowledge learnt from e-government can also be applied to m-government research.

\section{References}

Abaza, M., and Saif, F. 2015. "The Adoption of Mobile Government Services in Developing Countries," International Journal of Computer Science Issues (IJCSI) (12:1), p. 137.

Abu-Shanab, E., and Haider, S. 2015. "Major Factors Influencing the Adoption of M-government in Jordan," Electronic Government, an International Journal (11:4), pp. 223-240.

Abu-Shanab, E., and Shihadeh, S. 2016. "Factors Influencing G-SMS Adoption by Jordanian Citizens," Humanitarian Technology Conference (R1O-HTC), 2016 IEEE Region 1O: IEEE, pp. 1-6.

Ahmad, S. Z., and Khalid, K. 2017. "The Adoption of M-Government Services from the User's Perspectives: Empirical Evidence from the United Arab Emirates," International Journal of Information Management (37:5), pp. 367-379.

Al-Hujran, O., and Migdadi, M. 2013. "Public Acceptance of M-Government Services in Developing Countries: The Case of Jordan," E-Government Implementation and Practice in Developing Countries (242).

Almarashdeh, I., and Alsmadi, M. K. 2017. "How to Make Them Use It? Citizens Acceptance of MGovernment," Applied Computing and Informatics (13:2), pp. 194-199.

Almuraqab, N. A. S. 2017. "M-Government adoption factors in the UAE: A Partial Least Squares Approach," International Journal of Business and Information (11:4).

Alotaibi, R., Houghton, L., and Sandhu, K. 2016. "Exploring the Potential Factors Influencing the Adoption of M-Government Services in Saudi Arabia: A Qualitative Analysis," International Journal of Business and Management (11:8), p. 56.

Alotaibi, R., Houghton, L., and Sandhu, K. 2017. "Factors Influencing Users" Intentions to Use Mobile Government Applications in Saudi Arabia: TAM Applicability," International Journal of Advanced Computer Science And Applications (8:7), pp. 200-211.

Alotaibi, S., and Roussinov, D. 2017a. "User Acceptance of M-Government Services in Saudi Arabia: an SEM Approach," The Proceedings of European Conference on Digital Government 2017, p. 10.

Alotaibi, S., and Roussinov, D. 2017b. "Using Focus Group Method to Identifying Citizen Requirements To Saudi Mobile Government Services," 19th International Conference on e-Business and eGovernment.

Alrowili, T. F., Alotaibi, M. B., and Alharbi, M. S. 2015. "Predicting Citizens' Acceptance of MGovernment Services in Saudi Arabia an Empirical Investigation," Systems Conference (SysCon), 2015 9th Annual IEEE International: IEEE, pp. 627-633.

Alssbaiheen, A., and Love, S. 2015. "The Opportunities and Challenges Associated With M-Government as an E-Government Platform in KSA: A Literature Review," International Journal of Management \& Business Studies (5:2), pp. 31-38.

Aquino, K. C. 2015. "E-Learning and Disability in Higher Education: Accessibility Research and Practice by Jane K. Seale," The Review of Higher Education (38:2), pp. 305-307.

Baabdullah, A., Nasseef, O., and Alalwan, A. 2016. "Consumer Adoption of Mobile Government in the Kingdom of Saudi Arabia: The Role of Usefulness, Ease of Use, Perceived Risk and Innovativeness," Conference on e-Business, e-Services and e-Society: Springer, pp. 267-279.

Baabdullah, A. M., Alalwan, A. A., Rana, N. P., Dwivedi, Y., and Weerakkody, V. 2017. "Assessing Consumers' Intention to Adopt Mobile Internet Services in the Kingdom of Saudi Arabia," in: Twenty-third Americas Conference on Information Systems. Boston. 
Babullah, A., Dwivedi, Y. K., and Williams, M. D. 2015. "Saudi Citizens' Perceptions on Mobile Government (mGov) Adoption Factors," UKAIS, p. 8.

Cao, J., Crews, J. M., Lin, M., Deokar, A., and Nunamaker Jr, J. F. 2006. "Interactions between System Evaluation and Theory Testing: A Demonstration of the Power of a Mulitfaceted Approach to Systems Research," Journal of Management Information Systems (22:4), pp. 207-235.

Carroll, J. 2006. "'What's in It for Me?': Taking M-Government to the People," BLED 2006 Proceedings, p. 49.

Chatfield, A. T., and AlHujran, O. 2007. "E-government Evaluation: a User-Centric Perspective for Public Value Proposition," in: International Conference on e-Learning, e-Business, Enterprise Information Systems, and eGovernment. pp. 53-59.

Chen, C.-W., and Huang, E. 2006. "Predicting Taxpayers' Acceptance of Online Taxation Use," Proceedings of the 5th WSEAS International Conference on E-Activities, Venice, Italy: Citeseer.

Chen, Z.-J., Vogel, D., and Wang, Z.-H. 2016. "How to Satisfy Citizens? Using Mobile Government to Reengineer Fair Government Processes," Decision Support Systems (82), pp. 47-57.

Elsheikh, Y., and Hijjawi, M. 2016. "A Replicated Assessment of the Critical Success Factors for the Adoption of Mobile Government Services: the Case of Jordan," International Journal of Computer Science \& Information Technology (IJCSIT) (8:4), pp. 41-53.

ElSherif, H., Alomari, K., and Alkatheeri, A. 2016. "Mobile Government Services Satisfaction and Usage Analysis: UAE Government Smart Services Case Study," International Journal of Computer Science and Mobile Computing (5:3), pp. 291-302.

Faisal, M. N., and Talib, F. 2016. "E-Government to M-Government: A Study in a Developing Economy," International Journal of Mobile Communications (14:6), pp. 568-592.

Fontelo, P., Liu, F., and Yagi, Y. 2015. "Evaluation of a Smartphone for Telepathology: Lessons Learned," Journal of Pathology Informatics (6).

Freeman, R. E. 1984. "Strategic Management: A Stakeholder Approach. 1984," Boston: Harpercollins College Div.

Galvez, R. A., and Youngblood, N. E. 2016. "e-Government in Rhode Island: what effects do templates have on usability, accessibility, and mobile readiness?," Universal Access in the Information Society (15:2), pp. 281-296.

Gil-García, J. R. 2006. "Enacting State Websites: A Mixed Method Study Exploring E-Government Success in Multi-Organizational Settings," System Sciences, 2006. HICSS'O6. Proceedings of the 39th Annual Hawaii International Conference on: IEEE, pp. 76b-76b.

Gillenson, M. L., and Sherrell, D. L. 2002. "Enticing Online Consumers: An Extended Technology Acceptance Perspective," Information \& management (39:8), pp. 705-719.

Glood, S., Osman, W., and Nadzir, M. 2016. "Mobile Government Services among Iraqi Citizens in Rural Areas: A Pilot Study," Journal of Engineering and Applied Sciences (100:3), pp. 497-504.

Glood, S. H., Osman, W. R. S., and Nadzir, M. M. 2016. "The Effect of Civil Conflicts and Net Benefits on M-Government Success of Developing Countries: A Case Study of Iraq," Journal of Theoretical \& Applied Information Technology (88:3).

Hanna, N. K. 2016. "E-commerce as a techno-managerial innovation ecosystem: Policy implications," Journal of Innovation Management (4:1), pp. 4-10.

Jasimuddin, S. M., Mishra, N., and A. Saif Almuraqab, N. 2017. "Modelling the Factors that Influence the Acceptance of Digital Technologies in E-Government Services in the UAE: A PLS-SEM Approach," Production Planning \& Control (28:16), pp. 1307-1317.

Johnson, R. B., and Onwuegbuzie, A. J. 2004. "Mixed Methods Research: A Research Paradigm whose Time has Come," Educational Researcher (33:7), pp. 14-26.

Kelly, G., Mulgan, G., and Muers, S. 2002. "Creating Public Value," London, Cabinet Office.

Lee, W., and Rotoloni, B. 2013. "Emerging cyber threats report," Georgia Tech Cyber Secure Summit. 
Liu, Y., Li, H., Kostakos, V., Goncalves, J., Hosio, S., and Hu, F. 2014. "An Empirical Investigation of Mobile Government Adoption In Rural China: A Case Study in Zhejiang Province," Government Information Quarterly (31:3), pp. 432-442.

Mandari, H. E., Chong, Y.-L., and Wye, C.-K. 2017. "The Influence of Government Support and Awareness on Rural Farmers' Intention to Adopt Mobile Government Services in Tanzania," Journal of Systems and Information Technology (19:1/2), pp. 42-64.

Misra, D. C. 2009. "Make M-government an integral part of e-government: An agenda for action," Proceedings of TRAI conference on mobile applications for inclusive growth and sustainable development, pp. 78-86.

Misra, H. 2015. "Information Kiosk Based Indian E-Governance Service Delivery: Value Chain Based Measurement Modelling," The Journal of Community Informatics (11:1).

Molnár, T., Kő, A., and Mátyus, B. 2017. "Exploring Usability and Acceptance Factors of m-Government Systems for Elderly," International Conference on Electronic Government and the Information Systems Perspective: Springer, pp. 175-188.

Nguyen, T., Goyal, A., Manicka, S., Nadzri, M., Perepa, B., Singh, S., and Tennenbaum, J. 2015. IBM MobileFirst in Action for mGovernment and Citizen Mobile Services, (1st ed.). IBM Redbooks.

Nyemba-Mudenda, M., and Chigona, W. 2013. "Stakeholder Management in a Community mHealth Initiative in Malawi," Journal of Health Informatics in Africa (1:1), pp. 27-41.

Ohme, J. 2014. "The Acceptance of Mobile Government from a Citizens' Perspective: Identifying Perceived Risks and Perceived Benefits," Mobile Media \& Communication (2:3), pp. 298-317.

Ortega, J. L. 2015. "Relationship between altmetric and bibliometric indicators across academic social sites: The case of CSIC's members," Journal of Informetrics (9:1), pp. 39-49.

Rowley, J. 2011. "e-Government stakeholders-Who are they and what do they want?," International journal of Information management (31:1), pp. 53-62.

Saadi, M. R., Ahmad, S. Z., and Hussain, M. 2017. "Prioritization of Citizens' Preferences for Using Mobile Government Services: The Analytic Hierarchy Process (AHP) Approach," Transforming Government: People, Process and Policy (11:3), pp. 476-503.

Saxena, S. 2017. "Enhancing ICT Infrastructure in Public services: Factors Influencing Mobile Government (M-Government) Adoption in India," The Bottom Line (30:4), pp. 279-296.

Scholl, H. J. 2001. "Applying Stakeholder Theory to E-Government," in Towards the E-Society. Springer, pp. 735-747.

Teo, T. S., Srivastava, S. C., and Jiang, L. 2008. "Trust and electronic government success: An empirical study," Journal of management information systems (25:3), pp. 99-132.

Tian-Cole, S., Crompton, J. L., and Willson, V. L. 2002. "An empirical investigation of the relationships between service quality, satisfaction and behavioral intentions among visitors to a wildlife refuge," Journal of Leisure research (34:1), pp. 1-24.

Wang, C. 2014. "Antecedents and Consequences of Perceived Value in Mobile Government Continuance Use: An Empirical Research in China," Computers in Human Behavior (34), pp. 140-147.

Wirtz, B. W., and Birkmeyer, S. 2017. "Mobile Government Services: An Empirical Analysis of Mobile Government Attractiveness," International Journal of Public Administration (40:1), pp. 1-11.

World Bank. 2012. "World Development Indicators 2012," World Bank, Washington, DC.

Copyright: (C) 2018 Alshammari, Cheung and Messom. This is an open-access article distributed under the terms of the Creative Commons Attribution-NonCommercial 3.0 Australia License, which permits non-commercial use, distribution, and reproduction in any medium, provided the original author and ACIS are credited. 